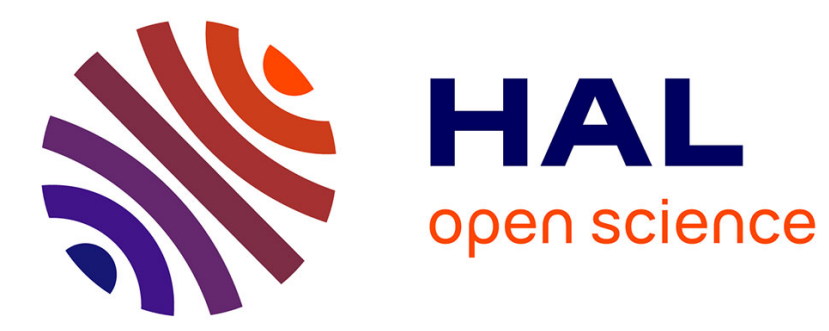

\title{
Exploring technologically, temporally and geographically-sensitive life cycle inventories for wind turbines: A parameterized model for Denmark
}

\author{
Romain Sacchi, Romain Besseau, Paula Perez-Lopez, Isabelle Blanc
}

\section{To cite this version:}

Romain Sacchi, Romain Besseau, Paula Perez-Lopez, Isabelle Blanc. Exploring technologically, temporally and geographically-sensitive life cycle inventories for wind turbines: A parameterized model for Denmark. Renewable Energy, 2019, 132, pp.1238-1250. 10.1016/j.renene.2018.09.020 . hal01876984

\section{HAL Id: hal-01876984}

https://hal-mines-paristech.archives-ouvertes.fr/hal-01876984

Submitted on 19 Sep 2018

HAL is a multi-disciplinary open access archive for the deposit and dissemination of scientific research documents, whether they are published or not. The documents may come from teaching and research institutions in France or abroad, or from public or private research centers.
L'archive ouverte pluridisciplinaire HAL, est destinée au dépôt et à la diffusion de documents scientifiques de niveau recherche, publiés ou non, émanant des établissements d'enseignement et de recherche français ou étrangers, des laboratoires publics ou privés. 
1 Exploring technologically, temporally and geographically-sensitive life 2 cycle inventories for wind turbines: a parameterized model for Denmark 3 Romain Sacchi $*^{\mathrm{a}}$, Romain Besseau ${ }^{\mathrm{b}}$, Paula Pérez-López ${ }^{\mathrm{b}}$, Isabelle Blanc ${ }^{\mathrm{b}}$

$4 \quad{ }^{a}$ Department of Planning, Aalborg University, Aalborg, Denmark

$5 \quad{ }^{b}$ Centre Observation, Impacts, Energie (OIE), MINES ParisTech, France

$6 \quad$ *Corresponding author: sacchi@plan.aau.dk

7 Wordcount: 8080

\section{Summary abstract}

In life cycle assessments of wind turbines and, more generally, of Renewable Energy Systems (RES), environmental impacts are usually normalized by electricity production to express their performance per kilowatt-hour. For most RES, manufacture and installation dominate the impacts. Hence, results are sensitive to parameters governing both impacting phases and electricity production. Most available studies present the environmental performance of generic wind turbines with assumed fixed values for sensitive parameters (e.g. electricity production) that often vary between studies and fail to reflect specificities of wind farm projects. This study presents an approach to build a comprehensive parameterized model that generates unique wind turbine life cycle inventories conditioned by technologically, temporally and geographically-sensitive parameters. This approach allows for the characterization of the carbon footprint of five sets of turbines in Denmark, where wind power is highly developed. The analysis shows disparities even between turbines of similar power output, mostly explained by the service time, load factor and components weights but also by background processes (evolution of electricity mix and recycled steel content). Project-specific inventories with technologically, temporally and geographically-sensitive parameters are essential for supporting RES development projects. Such inventories are especially important to evaluate highly-renewable electricity mixes, such as that of Denmark.

Keywords: wind turbine, parameterized model, life-cycle assessment, spatio-temporal variability, carbon footprint. 


\section{Introduction}

Increasingly competing with conventional energy sources, Renewable Energy Systems (RES) offer a way out of fossil fuels dependency and allow to reduce greenhouse gas emissions (GHG) associated with the generation of electricity [1]. The latter, together with heat production, still represents $42 \%$ of the world GHG emissions in 2015 per the International Energy Agency. The importance of RES is visible as the installed capacity of these systems increased by $30 \%$ worldwide in the last 40 years. However, their development must be intensified and combined with energy efficiency measures to reduce the GHG emissions at a global level, since the electricity demand has more than doubled during that same period [2].

In parallel to this development, numerous Life Cycle Assessment (LCA) studies analyzed the performance of RES and their increasing role in regional and national electricity mixes - see [3] in the context of Denmark - as well as at worldwide level - see [4]. LCA has proven to be a relevant tool to analyze the performance of different electricity generation systems [5-8]. LCA includes all the environmentally-relevant phases of the value chain of electricity production system: from the capture and conversion of primary energy, via the construction, maintenance and disposal of the plant to transform it, down to its distribution. As highlighted by Asdrubali et al. [9], the inclusion of all the phases of an energy system is important. Unlike for conventional fuel-based technologies, the highest contribution to environmental impacts of most RES corresponds to the manufacture and installation phases, while direct emissions during the use phase (i.e. electricity production phase) remain limited.

Given the rapid deployment of RES as well as the establishment of LCA as an adapted tool for assessing energy systems, this article suggests an approach to overcome current methodological issues in LCA applied to RES by generating tailored life cycle inventories (LCI) of wind turbines.

As the supply share of RES becomes significant in a national energy mix - as illustrated, for example, by recent statistics on gross electricity production and supply in Denmark [10] -, it seems paramount to use precise and correct data for modeling the manufacture and installation inventory as well as the production output during the use phase. Both elements strongly influence the end-results as the environmental performance of RES is usually expressed as the sum of the impacts of the manufacture, installation, maintenance and end-of-life inventories normalized by the electricity production. Zimmerman highlighted the importance of site specific parameters that can strongly influence the environmental performance of wind turbine [11]. For that reason, there is a need to move away from generic inventories and assumptions as they induce uncertainty in the results and fail to consider the diversity of designs and the effect of time and geography on the environmental performances of RES on the market. Among RES, tailored wind turbine inventories are notably worth to be developed, given the important spectrum of the market for the technology - for 
example, more than 1,500 different wind turbine models have been marketed as of today - and the temporal and geographical span over which they have been deployed. This diversity ideally calls for a differentiation in inventory modeling for each plant within the fleet of a studied area, as differences in technologies and materials used may lead to different end-results for some impact categories. This relates to the issue of parameter variability, affecting the modeling of product systems that have different technological and geospatial parameters. Padey et al. [12] have shown that such variables can have a considerable influence on the outputs of the LCA model of a wind turbine. In their review of LCA studies on wind turbines, Lenzen and Munksgaard [13] underline the contribution of variables such as the country of manufacture, the technology and the location of use on the overall energy intensity of the turbine. As they point out, the country of manufacture and the used technology indirectly affect the content of recycled metals in the turbines and its disposal options while the location of use (e.g. onshore or offshore) can affect the expected production output. Another study from 2004 from Lenzen and Wachsmann [14] confirms this outcome showing that differences in the background systems of two geographically-distinct economies (in this case, Germany and Brazil) could lead to a fivefold difference in environmental impacts for the manufacture of a same wind turbine.

In addition to variability-related issues at the manufacture and installation phases, the environmental performances of RES are also strongly influenced by the service conditions during their use phase. Indeed, the characterized emissions are normalized over the electricity production over time. This relates to the issue of parameter uncertainty, which results of the lack of knowledge on the conditions of use that affect the electricity production. Typical uncertain parameters for RES during their use phase would be their service time and their capacity factor $[12,13]$. The service time of a RES can be limited by harsh conditions of use. The capacity factor is generally function of wind speed distribution and the corresponding power curve for wind turbines. LCA studies and other Environmental Product Declarations (EPD) sometimes "guesstimate" the true value of such uncertain parameters and/or consider them fixed over time. For example, studies such as [14-17] assume a theoretical value for the capacity factor of wind turbines while Schleisner [18] leaves it simply unspecified. This can explain the spread in results found in meta-LCA studies, together with the uncertainty due to methodological choices $[9,19,20]$. It also leads to a misalignment between the environmental footprint theoretically calculated and the one observed a posteriori. The review work of Arvesen and Hertwich [21] concludes that real conditions of use are different from the theoretical ones used in most LCAs and that both capacity factors and service time of wind turbines are overestimated when characterizing their environmental performances.

Eventually, the use of simplifying assumptions for sensitive parameters at the different phases of the life cycle of the RES inevitably leads to ignore the influence of technology, time and geography on the LCI and associated life cycle impact results. The environmental performances calculated from generic inventories and production models likely contrast with what is observed. Moreover, as assumptions considered in generic inventories may differ from one study 
to another, generic studies cannot really offer a fair basis for comparison. Their usefulness for decision support is limited in the context of, for example, wind farm project development. In such case, knowing precisely the environmental gains expected from several alternatives for a project can foster its acceptance by the surrounding society and authorities.

This article presents a parameterized model able to generate tailored wind turbine LCI. By differentiating the inventory of each single RES according to the technological, temporal and geographical context of the product system, the approach allows first to tackle the issue of uncertainty in inventories, and second to consider variability in plant designs and in their electricity production over lifetime.

The LCI modeling approach presented in the next section allows for estimating the general material, energy and environmental performance of a whole fleet of wind turbines while keeping an important level of detail. It also accounts for the changes over time and space of certain background processes in the LCI, such as the evolution in material recycling rates or the changes in the electricity mixes at the manufacture phase. The benefit of such parameterized inventories is illustrated with the analysis of 1,401 cradle-to-grave LCI of wind turbines. Grouped in four categories of nominal power output with a subdivision for offshore installations, these wind turbines belong to different manufacturers, operate in distinct locations and are deployed at different points in time in Denmark. Their respective environmental performances are thereafter analyzed through their carbon footprint.

Several comparable wind turbines with a similar nominal power output may have significantly different environmental performances when the influence of technology, geography and time are considered in the LCI. The need for life cycle practitioners and energy project developers to move away from generic models could thereby be justified.

\section{Method}

This section describes the method used to generate individual cradle-to-grave LCI through a parameterized model following a four-step sequence. The applicability of the parameterized model is demonstrated with five sets of wind turbines in Denmark that have been operated before or until 2016.

The finality of the parameterized model developed in this study is to build wind turbine-specific inventories: it entails the definition of the total material and energy requirements of each phase of the wind turbine life cycle from its manufacture down to its disposal phase. As a first step, the method requires the acquisition of a fleet registry of wind turbines including key information such as the brand, model and coordinates of wind turbines that are located in the studied area, as well as their respective electricity production during their service time. Then, there is an attempt to match the information from such fleet registry with manufacturers specifications to obtain mass and dimension 
attributes. If a wind turbine cannot be matched with any manufacturer data, the method uses regression analysis to approximate mass and dimension attributes. As a second step, knowing the location of each wind turbine, the method can detect if the wind turbine is onshore or offshore. For offshore wind turbines, cartography tools are used to obtain the sea depth and distance to shore. These parameters are required to size the wind turbine foundation and the length of cables to connect to the national electricity grid. Third, knowing the size and mass attributes of the wind turbine, a specific supply, manufacture, installation, maintenance and disposal inventory is generated with the background support processes adjusted to the geographical and temporal context of the value chain, based on statistics of the appropriate geographical scope of analysis (i.e. regional, national or continental). At the last step, the method retrieves the registered electricity production and service time for the wind turbines already dismantled. For wind turbines currently in operation, their remaining service time is estimated based on the historical service time expectancy of past wind turbines (see Section 2.3). Additionally, their expected yearly electricity production is projected based on past registered production. The inventory of each wind turbine can be divided by the production output registered throughout its $u s e$ phase to obtain its environmental burden in relation to a $\mathrm{kWh}$ of electricity produced. This four-step sequence adopted by the model is graphically summarized in Figure 1.

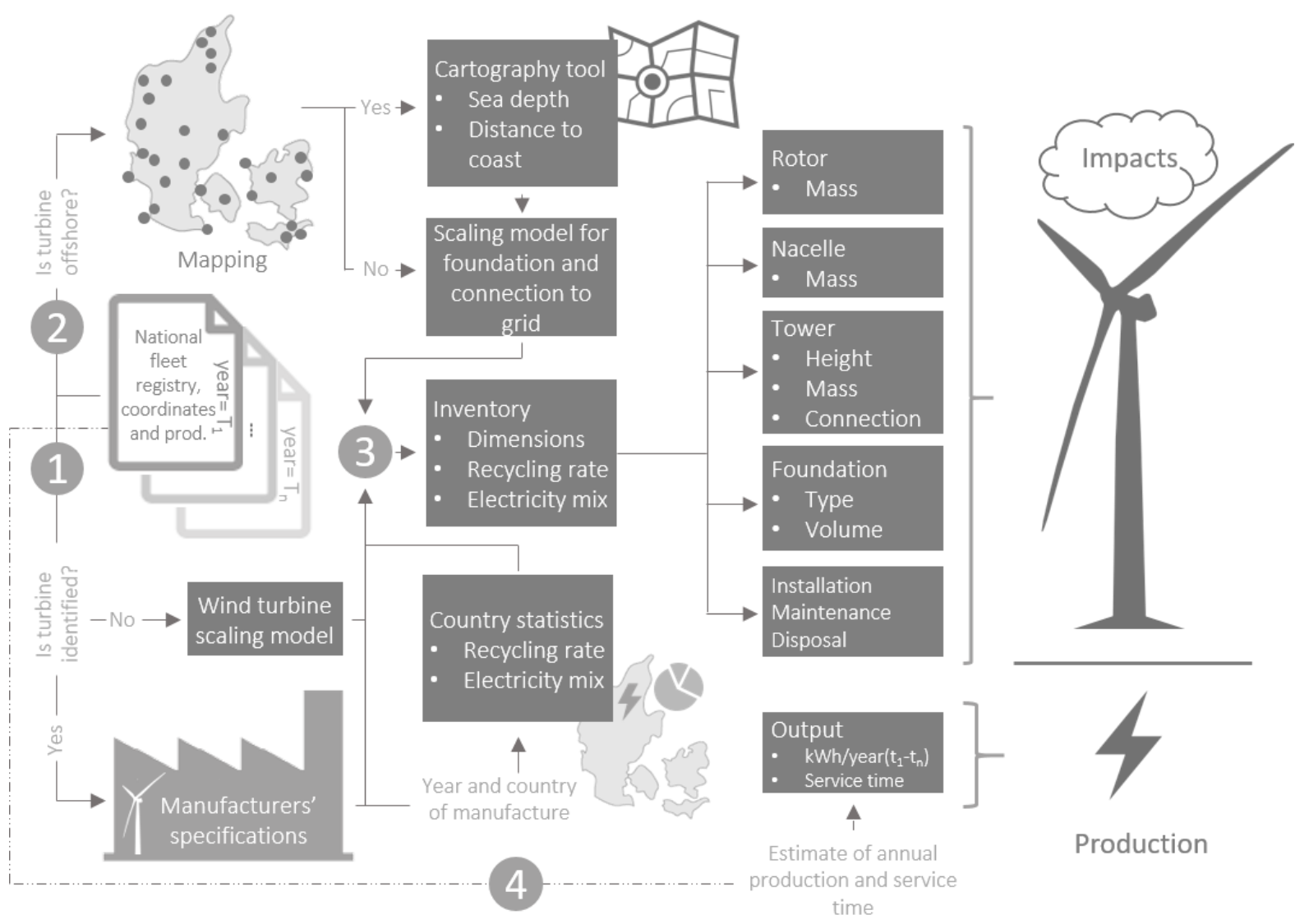


The approach has been applied to a selection of individual wind turbines grouped into five sets that have been operated in Denmark until 2016 as per the national wind turbines registry [22]:

- A "100-kW" set that comprises 543 onshore wind turbines with a nominal power output of [90-110] kW,

- A " $500-\mathrm{kW}$ " set that comprises 230 onshore wind turbines with a nominal power output of [450-550] kW,

- A "1-MW" set that comprises 370 onshore wind turbines with a nominal power output of [0.9-1.1] MW,

- A "2-MW" set that comprises 154 onshore wind turbines with a nominal power output of [1.8-2.2] MW.

- And a "2-MW offshore" set that comprises 104 offshore wind turbines with a nominal power output of [1.82.2] MW.

These five sets, totaling 1,401 wind turbines and described in Table 1, include different manufacturers and turbine models. These models have been manufactured at different points in time and operated in distinct locations. Their respective electricity production and service time are entirely or partially known, depending on whether they still operate in 2016.

Table 1: Sets of studied wind turbines.

\begin{tabular}{|l|c|c|c|c|c|}
\hline Set & $100 \mathrm{~kW}$ & $500 \mathrm{~kW}$ & $1 \mathrm{MW}$ & $2 \mathrm{MW}$ & $2 \mathrm{MW}$ offshore \\
\hline $\begin{array}{l}\text { Number of wind } \\
\text { turbines }\end{array}$ & 543 & 230 & 370 & 154 & 104 \\
\hline $\begin{array}{l}\text { Number of } \\
\text { manufacturers }\end{array}$ & $\begin{array}{c}20 \text { (including 1 } \\
\text { unidentified) }\end{array}$ & 7 & $\begin{array}{c}7 \text { (including 1 } \\
\text { unidentified) }\end{array}$ & 3 & 2 \\
\hline $\begin{array}{l}\text { Number of } \\
\text { models }\end{array}$ & $\begin{array}{c}15 \text { models } \\
\text { uncluding 3 } \\
\text { (including 2 } \\
\text { unidentified) }\end{array}$ & $\begin{array}{c}28 \text { models } \\
\text { (including 2 } \\
\text { unidentified) }\end{array}$ & $\begin{array}{c}13 \text { models } \\
\text { including 3 } \\
\text { unidentified) }\end{array}$ & 3 \\
\hline $\begin{array}{l}\text { Start of service } \\
\text { time }\end{array}$ & 1980 to 2004 & 1989 to 2013 & 1993 to 2005 & 1996 to 2016 & 2000 to 2003 \\
\hline $\begin{array}{l}\text { Operating in } \\
2016\end{array}$ & $3.5 \%$ & $95 \%$ & $98 \%$ & $93 \%$ & $100 \%$ \\
\hline
\end{tabular}

A tailored cradle-to-grave LCI is built for each of these wind turbines with the parameterized model following the above-mentioned steps. These steps are detailed in the next sub-sections. The inventories are stored in a Python dictionary and the material and energy requirements are solved thereafter using the LCA framework Brightway [23]. Finally, each inventory is characterized regarding the global warming impact category with a hundred-year time horizon and expressed as GHG emissions (mass of emissions of $\mathrm{CO}_{2}$-eq.) using the characterization factors provided by the Intergovernmental Panel on Climate Change [24].

\subsection{Modeling the foreground processes}

The following sub-sections describe the inventory modeling of foreground processes included in the manufacture, installation, use, maintenance and disposal phases of the life cycle. 


\subsubsection{Components specifications: manufacturers data and scaling models}

The model considers onshore and offshore wind turbines as a group of components to be assembled: the tower, the nacelle, the rotor (including the hub and the blades), the transformer and the connection to the substation. Onshore plants have a concrete-based foundation while offshore plants are assumed to be connected to the sea bed by a steelmade monopile foundation - which equips 70 to $80 \%$ of the offshore installations in Denmark [25] - via a transition piece.

Almost all the wind turbines in the studied sets have been identified and linked to manufacturers data, from which precise dimensions and weights of the different components are obtained. The dimensions of the remaining few wind turbines that the model could not identify are estimated using a set of scaling models based on correlations between attributes of the turbine components that are presented below.

\subsubsection{Scaling models: from wind turbine nominal power to mass and size attributes}

The approach described in [12] is adapted to build a series of scaling models for onshore and offshore plants against the mechanical and physical specifications of 1,525 unique models provided by The Wind Power database [26]. Based on observed physical correlations between components, the scaling models estimate a set of dimensions and masses for the foundation, tower, nacelle and rotor using the nominal rated power of the wind turbine as input. Details on the correlations between the nominal power output and the different components of a wind turbine are available in the Supporting information document. To illustrate the idea behind the correlations used by the scaling models, Figure 2 shows the sequence used to obtain the rotor weight of an unidentified wind turbine. The rotor diameter is first estimated based on the nominal power output of the wind turbine, since the correlation between the two parameters is statistically significant (i.e. a Pearson correlation coefficient superior to 0.75 ). Once the rotor diameter is known, it can be used to obtain its mass.
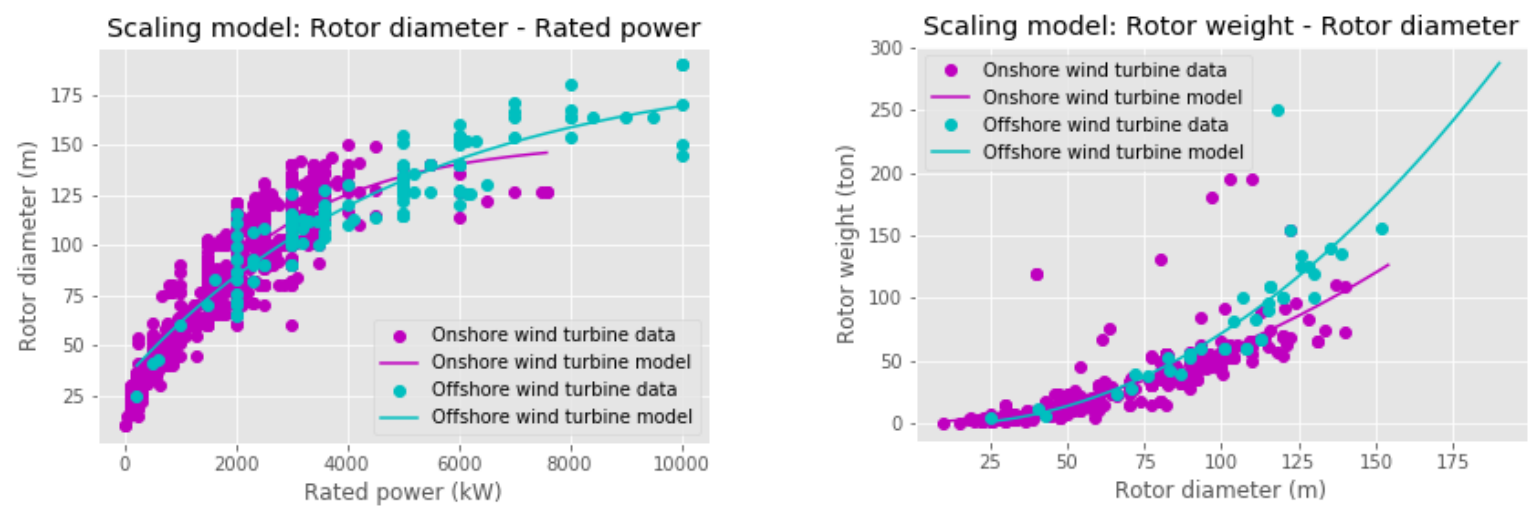

Figure 2: Correlation between nominal power and rotor diameter (left) and correlation between rotor diameter and rotor weight (right). 


\subsubsection{Sizing the offshore foundation}

For offshore wind turbines, the parameterized model uses an additional model built from a technical project description report on offshore installations in Denmark [25]. A schematic representation of an offshore installation as considered in this study is available in the Supporting information document. The scaling model returns the material and energy requirements for the supply and installation of a steel-made monopile foundation with the transition piece, including the grouting between the foundation and the transition platform, the casting of concrete at the bottom and the use of rocks to prevent degradation from scouring. The overall monopile height is modelled as being equal to the part inserted in the sea bed (conditioned by the nominal power output of the wind turbine and its weight), the part between the sea bed and the surface (a cartographic tool is used to return the sea depth for the location of each offshore installation) and the part between the surface and the transition platform (assumed to be 9 meters above the surface, regardless of other parameters).

\subsubsection{Sizing the electric connection to the national electricity grid}

Additionally, the model estimates the amount of materials necessary to connect wind turbines to the national electricity grid considering both cables and power transformers. For offshore wind turbines, the amount of cable necessary to connect to the coast is calculated considering a typical grid connection scheme found in Horns Rev wind farms, off the western coast of Jutland (Denmark) with a $33 \mathrm{kV}$ inter-array cabling voltage and a shore connection voltage of $150 \mathrm{kV}$ - or directly at $33 \mathrm{kV}$ if the wind farm power output is lower than $30 \mathrm{MW}$ [27]. The assessed cable sections are based on the transport capacity of Nexans $33 \mathrm{kV}$ and $150 \mathrm{kV}$ copper-based product range [28,29]. The cable length depends on the distance between the wind turbine and the central transformer of the farm (which is roughly assumed to be positioned at the centroid of the farm) and the distance between the farm and the coastline. Based on such distance, requirements in terms of copper for cabling and the energy for laying the cable - with ship consumption figures from the company [30] - are approximated. It is important to note that this estimation may differ from reality for at least two reasons. First, there is a tendency to use higher voltage or HVDC technology when distance increases. Second, the inter-array cabling and the central transformer location also strongly depend on topology and aluminum-based cables are sometimes used instead of copper. Additionally, the model considers a medium voltage power transformer for each wind turbine to reach the intra-array voltage of $33 \mathrm{kV}$ and a high voltage power transformer for the wind farm to reach the shore connection voltage of $150 \mathrm{kV}$. Inventories for power transformers are based on ABB Environmental Product Declarations [31,32]. Fugitive emissions of sulfur hexafluoride, an extremely potent greenhouse gas often used in circuit breakers for its exceptional electrical insulation properties, have not been accounted for in the model. This choice is justified by the fact that even if $\mathrm{SF}_{6}$ emissions are strongly underestimated, the impacts on climate change remains negligible compared to the GHG emissions from wind power as detailed in the SI document. Moreover, there are 
important uncertainties regarding the nature of the gas used with some alternatives being developed [33,34] and the amount of gas used in circuit breakers and the leakage rate over the lifecycle have been strongly reduced over time $[35,36]$. The size of each medium power transformer depends on the corresponding wind turbine nominal power, while the size of the high-voltage transformer depends on the total nominal power of the wind farm. In coherence with the EPD, the lifetime of the shore connection infrastructure is 35 years for the power transformer and 40 years for the cables. Regarding onshore wind turbines, they connect to the national grid at medium voltage. For this reason, a medium voltage power transformer associated to each turbine is also considered, as well as a cable with a length conditioned by the nominal power output of the wind turbine it connects to.

\subsubsection{Estimating mass distribution of wind turbine components according to the nominal} power

The detailed material and assembly inventories of six wind turbine models $(33 \mathrm{~kW}, 150 \mathrm{~kW}, 600 \mathrm{~kW}, 800 \mathrm{~kW}$ and two $2 \mathrm{MW}$ ) provided by [37] are used to obtain the materials percentage distribution by mass for the different wind turbine components (e.g. ratio glass fiber-epoxy in the blades). The calculated mass ratios are used by the model to estimate the unknown quantities of the different materials necessary to produce the wind turbine components. These quantities are obtained by interpolating between the known ratios. For the material and energy flows that are not significantly correlated to the mass of the components, the model extrapolates their quantities based on the nominal power output of the wind turbine. For example, based on the provided inventories, $0.5 \mathrm{kWh}$ of electricity per $\mathrm{kg}$ of material is needed to assemble the wind turbine components together. Once all the quantities for the different flows of material and energy are calculated, they are linked to corresponding supply market datasets in the ecoinvent 3.3 LCI database [38]. Market datasets in ecoinvent provide "cradle-to-supply" inventories for commodities for a specific regional area. The environmental burden that relates to the geographical variation in production technology and modes of distribution within that area is considered based on the respective market share of countries that supply these commodities. The specific mapping between inventory flows and the ecoinvent market datasets can be consulted in the section 1.4 of the Supporting information document.

\subsubsection{Installation, maintenance and disposal}

Requirements for specific activities such as road construction for onshore installations or sea bed drilling and the hammering of the monopile for offshore installations are interpolated based on the nominal power output of the wind turbine which correlates rather well with its mass and dimensions. Background processes associated to the assembly operations are provided by the ecoinvent 3.3 LCI database [38]. Furthermore, regular maintenance is considered with the change the lubrication oil in the gearbox and transport of technicians. However, exceptional maintenance involving 
material replacement has not been accounted due to lack of data. Finally, different disposal options are considered depending on the nature of the materials. While concrete, fiberglass and aggregates are disposed in landfills, steel (excluding reinforcing steel), thermoplastics and copper cables are supplied to the corresponding scrap markets. This study follows the polluter pays principle: the environmental burden associated to the treatment of waste materials is accounted for. These operations are further described in the Supporting information document.

\subsection{Adjusting background processes}

The model also adjusts the background processes in the inventory of the wind turbines in function of the location and time of manufacture. This was relatively simple in this case study since all the wind turbines have been manufactured by medium and large manufacturers in Denmark that rely on supplies from neighboring countries, for which data and background inventory datasets are abundant.

\subsubsection{Geographically-adjusted supply markets}

The model is designed to be as location-specific as possible, resorting to global supply markets last. First, the supply of energy and materials is geographically-adjusted: electricity and heat are supplied by the Danish market, ferrous and non-ferrous metals are supplied by the German market, plastics components by the European market and the materials that cannot be supplied by a local market are eventually supplied by the global market.

\subsubsection{Time-adjustment of the background electricity supply}

To reflect the influence of time on the manufacture and assembly inventories, the model adapts specific energyintensive background processes to the year of manufacture. It is the case with electricity. Danish-average electricity mix datasets with supplying technologies, imports and network losses are built to the year of manufacture of each wind turbine. The electricity mixes are based on historical time series provided by the Danish Ministry of Energy [10]. The time series of electricity supply mix are available in the Supporting information document.

\subsubsection{Time-adjustment of the background steel supply}

The provision in primary and secondary (recycled) low-alloyed steel for the manufacture of the tower and the different components inside the nacelle is also adjusted. Germany, the main supplier of steel in Europe, has been selected as the primary supplier of steel, since Denmark does not have any domestic production. As secondary steel has a lower embodied energy than primary steel, the recycling rate for steel has been adjusted to the year of manufacture of the wind turbine to reflect the evolution in terms of recycling in the steel industry over time [39]. The time series of primary and secondary steel supply mix are available in the Supporting information document. 


\subsection{Modeling the electricity production}

The two following sub-sections describe the approach used to model the electricity production during the life cycle use phase of the wind turbines.

\subsubsection{Estimation of the service time for operating turbines}

There are no clear correlations between the service time observed on dismantled wind turbines and any of their technical specifications (brand, model, nominal power, installation date, etc.). Also, the 40 years of data from the Danish wind turbines registry did not suffice to detect a statistical pattern in that regard. The service time of a turbine seems to be conditioned by the relation between the marginal cost of maintenance and the electricity price of the supplied area, as indicated by a report commissioned by the Danish Ministry of Energy on the topic [40]. The plant owner tends to operate the wind turbine if the marginal cost of maintenance is inferior or equal to the marginal income of production. Variable maintenance costs for the turbines are not known to the authors and future electricity prices remain difficult to predict. Regardless of the characteristics, the wind turbines still in operation in 2016 are given a service time in line with what has been observed on the 3,121 turbines that have been decommissioned to date: a random value comprised within a normal distribution centered around 18-19 years with a standard deviation of 4, see Figure 3 .

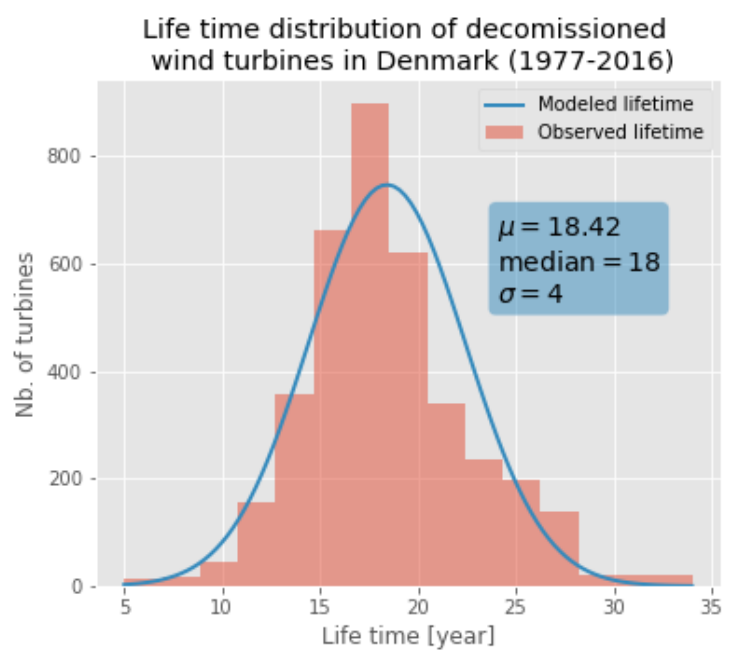

Figure 3: Distribution of the service time of decommissioned turbine in Denmark up to 2016.

\subsubsection{Estimation of the remaining production for operating turbines}

The electricity production registered for the wind turbines that are already decommissioned is used. As described in Table 1, it is worth underlining that most of the wind turbines in the studied sets are still operating in 2016 . The parameterized model needs to estimate the remaining electricity production of the wind turbines still active in 2016. With a service time estimated as per Section 2.3.1, the overall electricity production during the use phase is obtained by 
289 adding the product between the median value of the registered production and the estimated remaining years of service

290 time to the production that has already been registered. The median annual production value is used instead of the

291 average value to avoid considering the first year of production. Indeed, the first year of production may return a much

292 lower production figure than the following years if the wind turbine started operating towards the end of the year.

\section{Results and discussion}

294 Thanks to the parameterized model generating tailored onshore and offshore wind turbines LCI, it is now possible to analyze the environmental performances of the 1,401 wind turbines studied in regard to the global warming impact category as presented in Figure 4 hereunder. 
a) $100 \mathrm{~kW}$ set

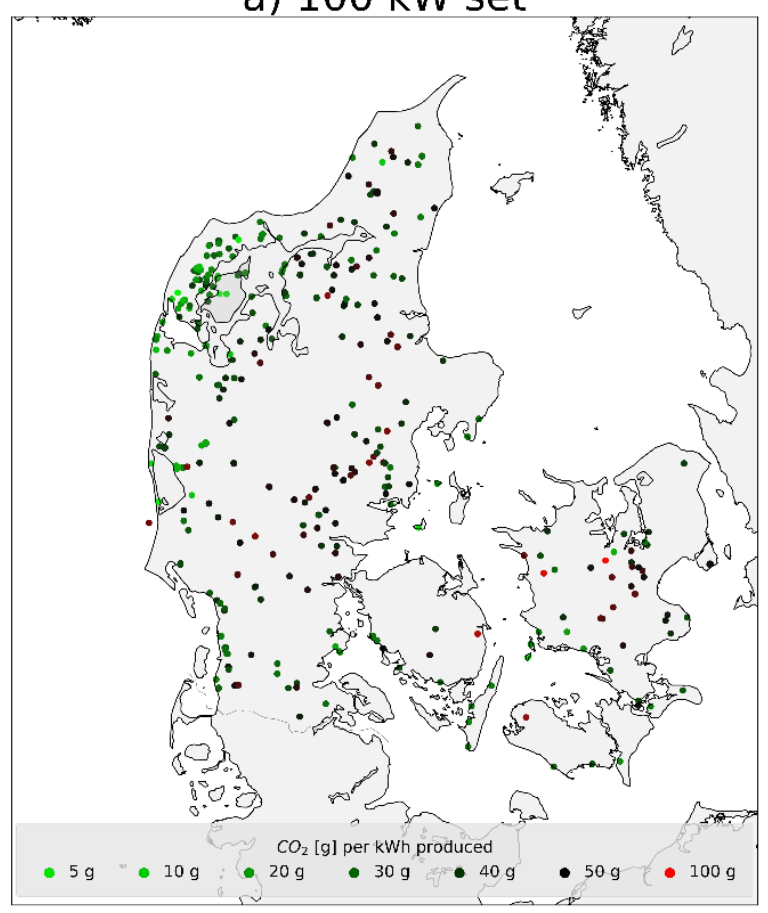

c) $1 \mathrm{MW}$ set

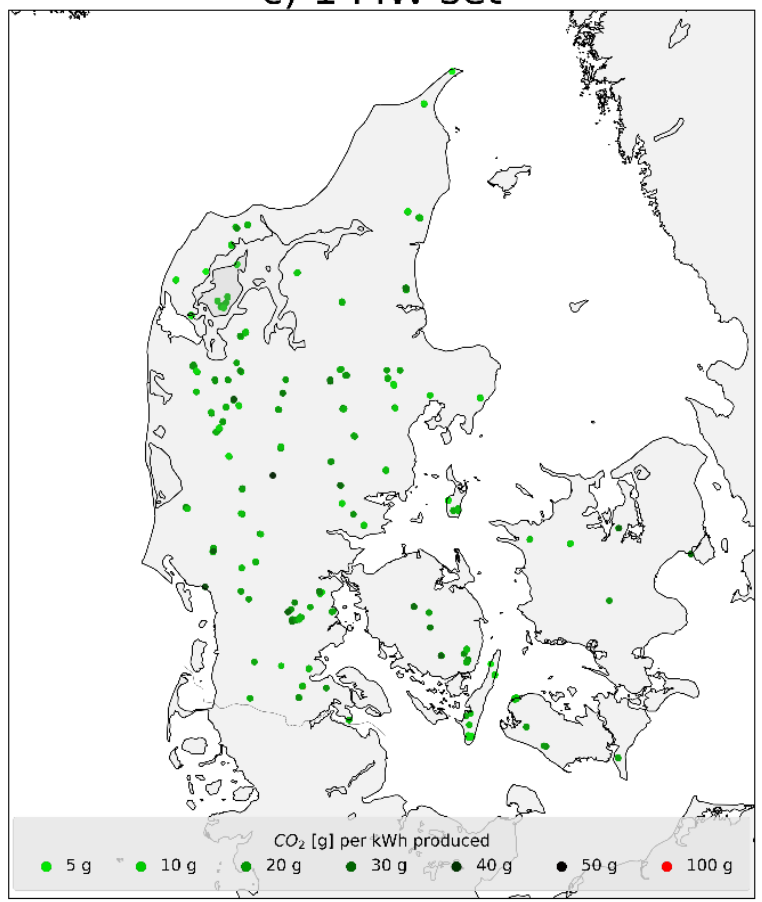

b) $500 \mathrm{~kW}$ set

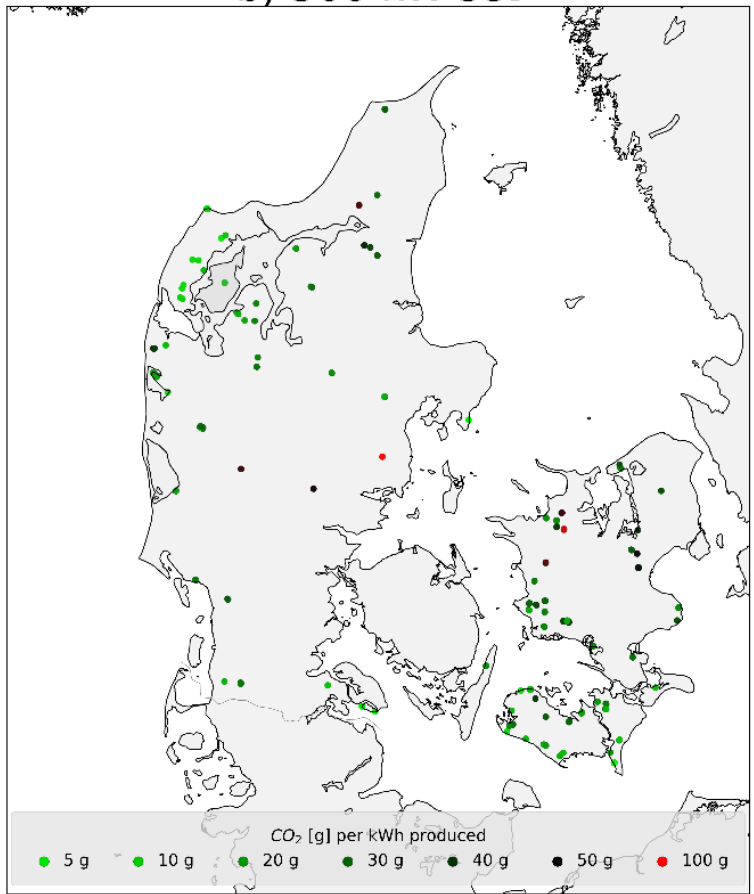

d) $2 \mathrm{MW}$ set (onshore and offshore)

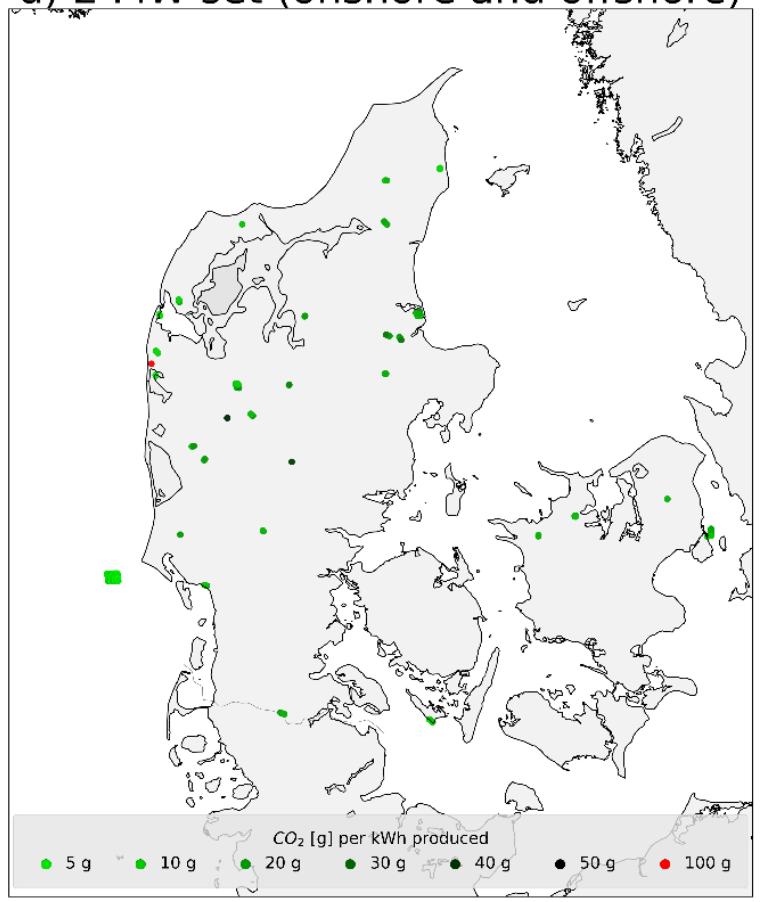

Figure 4: Map of the studied wind turbines and associated GHG emissions per kWh. Wind turbines with GHG emissions per kWh above 100 grams are not displayed (27 wind turbines of $100 \mathrm{~kW})$

The GHG emissions of wind turbines are conditioned by their material and energy requirements all along the life cycle.

These requirements are particularly dependent on the nominal power output and dimensions of the wind turbine.

Figure 5.a shows economies of scale where GHG emissions are marginally decreasing as the nominal power of the wind turbine increases: progress in terms of design and technology allowed reaching higher nominal power outputs while increasing the energy and material efficiency. While the nominal power output is multiplied by 20 between the wind turbines that belong to the $100-\mathrm{kW}$ and $2-\mathrm{MW}$ sets, the median GHG emissions per life cycle are only 10 times as 
important. For 2-MW systems, offshore wind turbines emit slightly more GHG than most onshore wind turbines during the manufacture and installation phase due to heavier foundations. However, some $2 \mathrm{MW}$ onshore wind turbines have a larger rotor to increase the turbine production, which leads to a higher impact than that of the offshore ones. This increased impact is associated with the higher and heavier tower required to support the larger rotor. These aspects are further discussed in Section 3.1.

a) GHG emissions per wind turbine installed

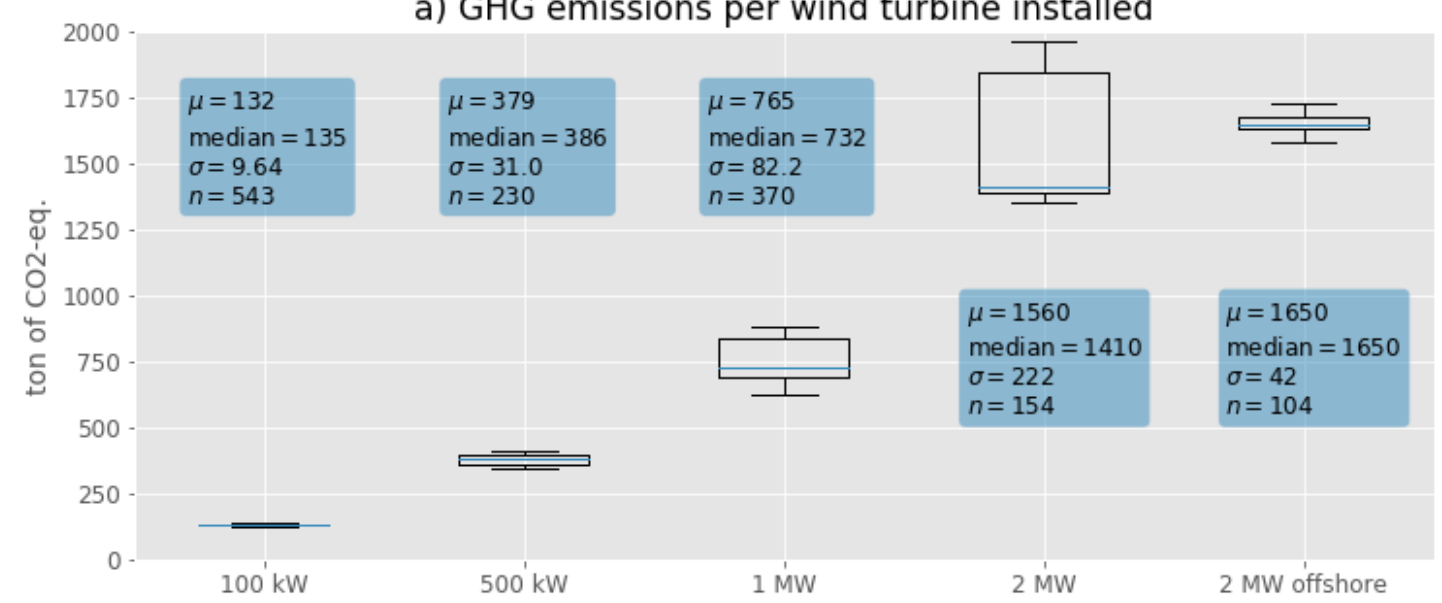

b) GHG emissions per kWh generated

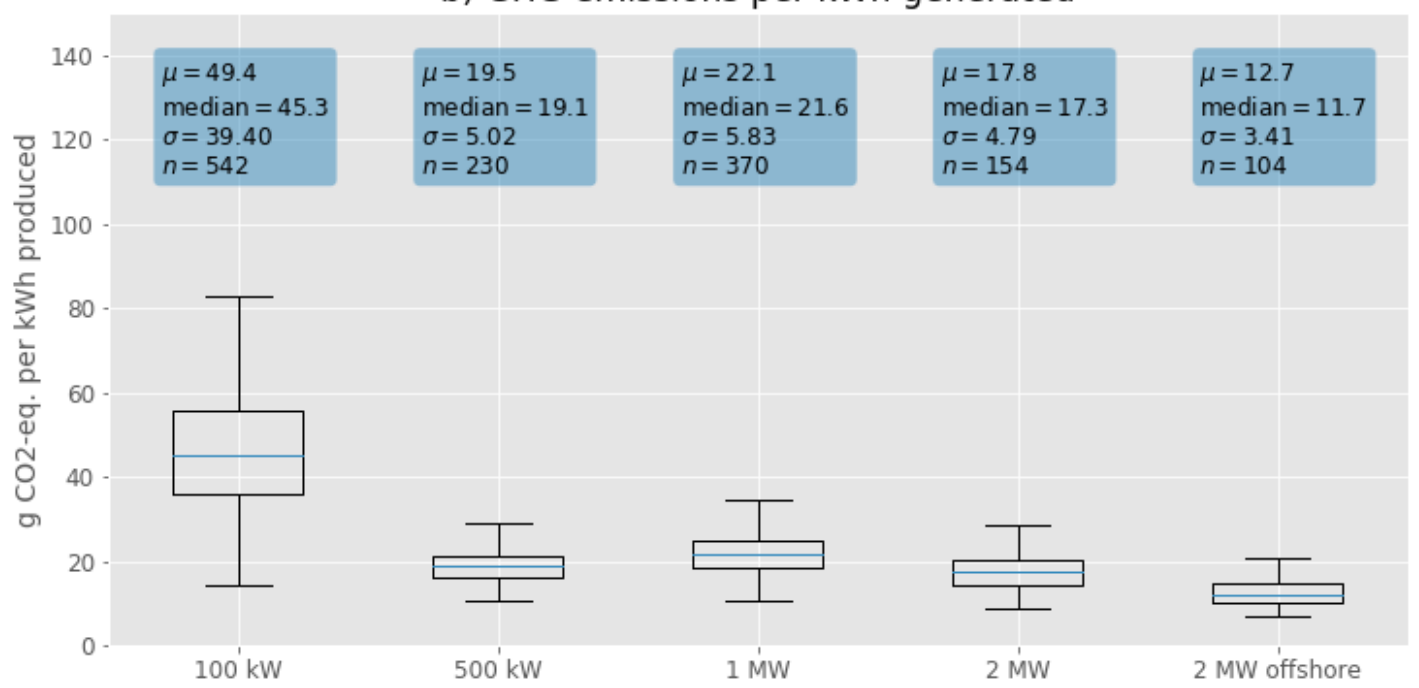

Figure 5: Statistical distribution of wind turbines GHG emissions per power category expressed as: a) emissions per life cycle and b) emissions per $k W h$ produced. The blue horizontal line is the median value. Vertical rectangles represent $50 \%$ of the distribution. Vertical black intervals represent $90 \%$ of the distribution. Outlying values are computed but not displayed.

When considering GHG emissions per kWh of electricity produced, there are two combined effects: on the one hand, increased power output leads to increased electricity production and, on the other hand, material and energy requirements per $\mathrm{kW}$ decrease for wind turbines with higher power output (that is, material and energy requirements do not increase linearly with power output). According to the results shown in Figure 5.b, these effects lead to a reduction 
of the GHG emissions per kWh produced as the nominal power output of the wind turbine increases. However, the GHG emissions reduction between the sets is marginally decreasing as the nominal power output increases. While such reduction is significant between the $100-\mathrm{kW}$ and $500-\mathrm{kW}$ sets, it is less so between sets of wind turbines with larger nominal power outputs. The statistic relation between nominal power output and electricity production is later discussed and graphically described in Figure 8. A lower carbon footprint for offshore wind turbines explained by a better wind resource is observed, as described in Section 3.3.

There is a high variance in the results of the $100-\mathrm{kW}$ set due to an important variability of electricity production that can be partly explained by technological improvements as these turbines where the first to be develop and installed in Denmark. Additionally, some wind turbines with outlying performances heavily weight on the average value of the 100-kW set distribution that exceeds 3,000 grams $\mathrm{CO}_{2}$-eq. per $\mathrm{kWh}$. This is not representative of the actual performance of the set (i.e. unfairly high, in that case) and it is due to wind turbines that have served as prototypes and have produced very few electricity or that presented serious defects. The median value, unaffected by outlying values, is a more useful statistic in this case. The distribution is narrower for the four other sets, but their standard deviation values remain important: at best, the standard deviation value represents a fourth of the average value for the 1-MW set, with a min-max interval going from 10 to 56 grams of $\mathrm{CO}_{2}$-eq. per $\mathrm{kWh}$ produced. As wind power can compete for investment with other "low-carbon" technologies (e.g. hydro, solar, nuclear), such spread in the results is meaningful and understanding its cause is important. The variance is believed to find roots in the model parameters that are of technological, temporal and geographical nature, as the next subsections discuss.

\subsection{Technological influence}

This section looks at how the choice of design and technology affects the material and energy-efficiency of wind turbines. In this case, GHG emissions are expressed per $\mathrm{kW}$ of nominal power output for each set of wind turbines produced at a given year of manufacture. Setting a fixed year of manufacture in reference to a $\mathrm{kW}$ of nominal power output, as opposed to a $\mathrm{kWh}$ of electricity produced, allows testing the influence of technological parameters while keeping spatial and time-related parameters fixed. Parameters that relate to technological aspects, such as the design and the intended application (onshore, offshore) of the wind turbine seem to affect the use of materials and energy and consequently, the amount of GHG emissions per $\mathrm{kW}$ of power output. Average and median GHG emissions per $\mathrm{kW}$ for each set of turbines are shown in Figure 6. The results seem very sensitive to technological parameters, notably for the smaller wind turbines contained in the $100-\mathrm{kW}$ set.

As the wind turbine industry developed, the models on the Danish market became fewer along with the number of producers. But the models increased in power and size. This led to less material required and less variance in terms of 
impacts associated to the manufacture phase per $\mathrm{kW}$ of nominal power output. Indeed, the effect of design and materialintensity is visible on early models with a low nominal power output, explained by a wider spectrum of designs and technologies. For example, the amount of low-alloy steel needed for the wind turbines in the $100-\mathrm{kW}$ set is about 150 $\mathrm{kg}$ per $\mathrm{kW}$ of nominal power output, with large variations around that value. For the wind turbines in the 2-MW set, this value decreases down to approximately $100 \mathrm{~kg}$ of steel per $\mathrm{kW}$ on average. It is also the case in regard to the design of blades and the amount of glass fiber-reinforced plastics required for their manufacture: while an average of $9 \mathrm{~kg}$ of reinforced plastics are needed per $\mathrm{m}^{2}$ of swept area on wind turbines from the $100-\mathrm{kW}$ set (with a total swept area of $320-350 \mathrm{~m}^{2}$ ), that figure goes down to $5.5 \mathrm{~kg}$ for the wind turbines that belong to the 2-MW set (with a swept area of 5000-7000 $\mathrm{m}^{2}$ ). As illustrated by Figures 5.a and 6,2 MW wind turbines show a relatively wider dispersion than 500 $\mathrm{kW}$ and $1 \mathrm{MW}$ wind turbines that is explained by differences of rotor size and tower height within this set. Two thirds of those turbines have rotor diameters of 70-80 m, tower heights between 60-80 m weighting about $160 \mathrm{t}$ and impacts of $1400 \mathrm{tCO}_{2}$-eq, approximately. Wind turbines belonging to the other third have larger rotor diameters of 85-100 $\mathrm{m}$, which logically involve higher tower heights of 75-110 m weighting between 200-270 t and higher impacts close to $1800 \mathrm{tCO}_{2}$-eq. This higher impact is compensated by a higher load factor when expressing the environmental performance in terms of $\mathrm{gCO}_{2}-\mathrm{eq} / \mathrm{kWh}$ produced (see Section 3.3).

Regarding offshore wind turbines, they have a higher global warming impact per $\mathrm{kW}$ of nominal power output during the installation phase and the supply of the foundation than equivalent onshore wind turbines (i.e. with similar rotor dimension). For instance, the characterized LCI of the offshore version of the VESTAS V80 model results in higher GHG emissions per $\mathrm{kW}$ of nominal power output than its onshore counterpart $\left(0.83\right.$ tCO ${ }_{2}$-eq $/ \mathrm{kW}^{\text {against }}$ $0.70 \mathrm{tCO}_{2}-\mathrm{eq} / \mathrm{kW}$, on average). These assertions are discussed in the next sections where the environmental impacts are expressed in relation to the effective production of electricity to reflect the influence of wind availability and service time. The material and energy requirements related to underwater foundations (between 130 and 190 tons of steel supply for the monopile foundation mostly) bear a higher environmental burden than the onshore alternative (350 cubic meters of in-situ concrete, 27 tons of reinforcing steel, 8,000 meter-year of road and associated handling operations). This difference becomes increasingly important as the sea depth increases. In relation to a sea depth of 10 meters, the GHG impact of an offshore VESTAS V80 installed in the Horns Rev wind farm would approximately increase by $1 \%$ per additional meter of sea depth. Upcoming floating platforms may in the future further increase this difference with onshore installations, despite better wind resources found away from the coastline, according to [41]. However, floating platforms will be less sensitive to sea depth and allow installation of wind turbines in deeper seas. 


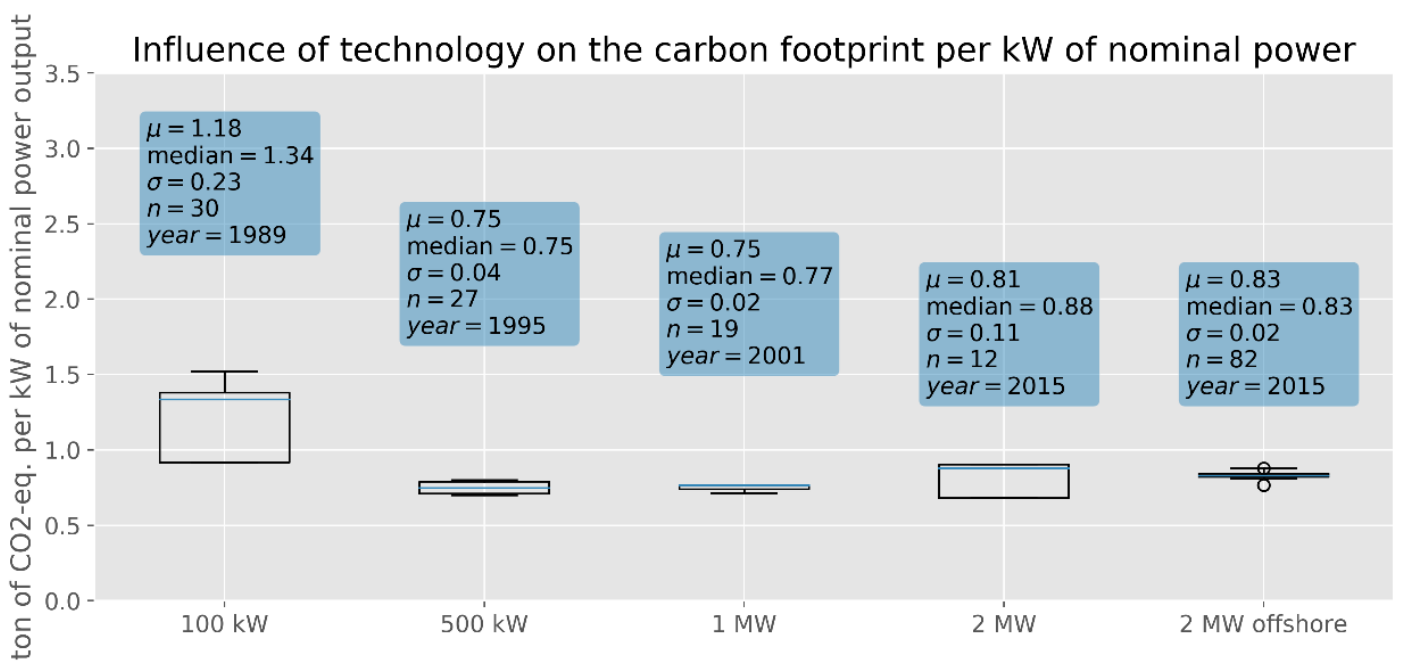

Figure 6: Statistical distribution of wind turbine carbon footprint per kW of nominal power per power category. The blue horizontal line is the median value. Vertical rectangles represent $50 \%$ of the distribution. Vertical black intervals represent $90 \%$ of the distribution. Outlying values are computed but not displayed.

\subsection{Temporal influence}

\subsubsection{The year of manufacture}

In this section, the influence of adjusting the background processes (electricity and steel) at the manufacture phase to the year of manufacture on the GHG emissions of wind turbines is assessed. To do so, the GHG emissions of a unique wind turbine model are plotted in reference to a $\mathrm{kW}$ of nominal power output for different years of manufacture. This allows disregarding the influence of technology (as only one model is considered) or location of use and wind availability (as the GHG emissions are expressed regarding one $\mathrm{kW}$ of nominal power output). Figure 7.a shows the GHG emissions per $\mathrm{kW}$ of nominal power output obtained according to the parameterized model for the VESTAS V80, produced from 1995 to 2015 with the same manufacture inventory. In parallel, the figure also shows with a base 100 Index in 1996 the relative change in the GHG emissions for the supply of Danish electricity and German steel used for the manufacture of the wind turbine. The GHG emissions per $\mathrm{kW}$ of nominal power output decreased by $11 \%$ during the analyzed period, exclusively due to the evolution of electricity and steel background processes. The GHG emissions associated with Danish electricity decreased in the same period by almost $80 \%$ and the German steel by $5 \%$. 
a) Relative evolution of the Danish electricity mix and German steel carbon footprints and impact on the carbon footprint of a typical Vestas wind turbine per $\mathrm{kW}$.

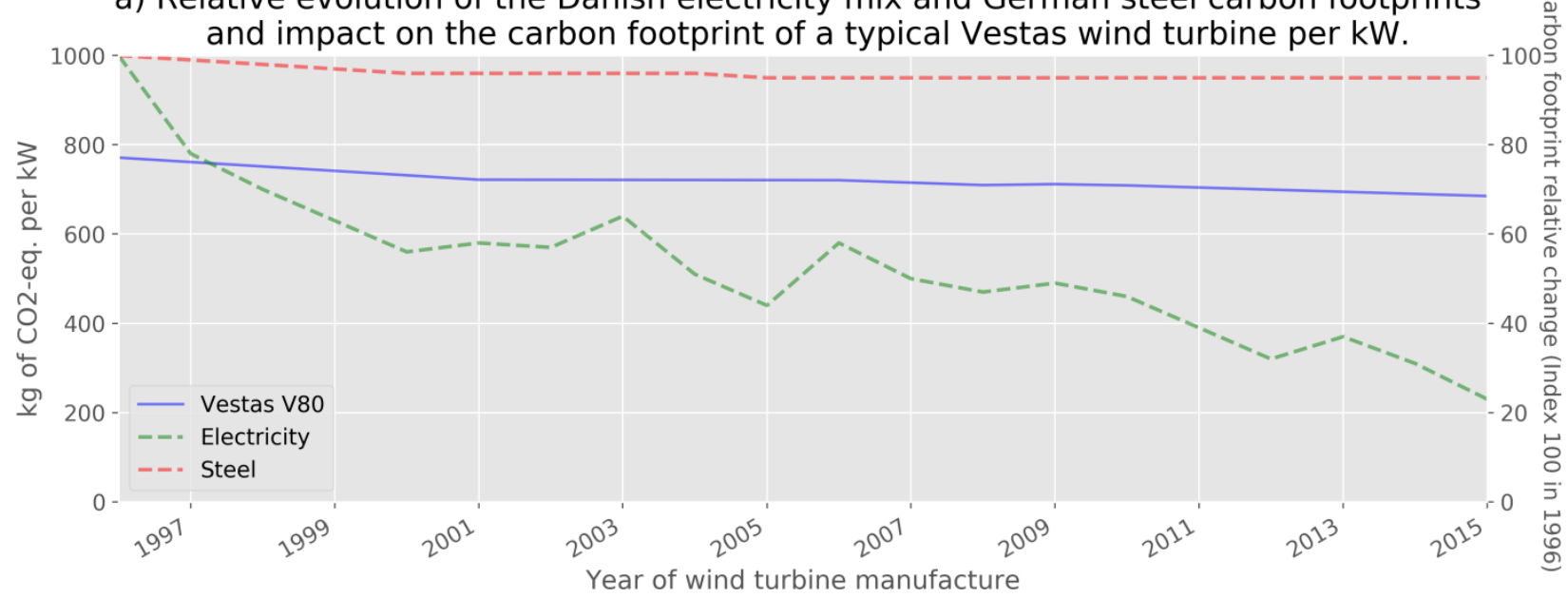

b) Influence of turbine lifetime on the carbon footprint per kWh produced, grouped by models manufactured in 2002 with 3,000 hours at full load

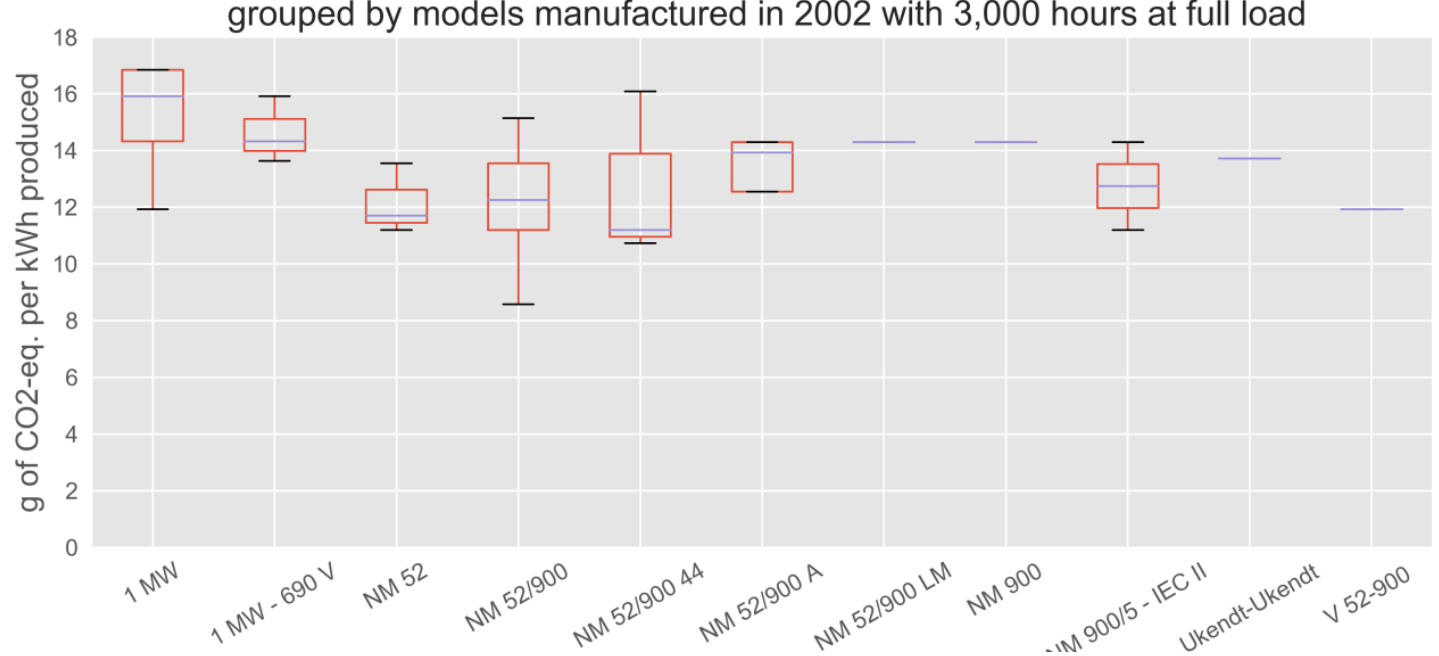

Figure 7: Graphical depiction of the temporal influence on the GHG emissions of wind turbines.

Virtually all wind turbine models rely on the extensive use of steel and electricity for manufacture. Hence, the decarbonization of support systems (i.e. electricity, heat) and materials play a major role in reducing the GHG emissions associated to the life cycle of wind turbines. In fact, in the case of Danish electricity, the reduction of $80 \%$ of its GHG emissions within the last 20 years is to a large extent due to the expansion of wind power in the national supply mix over the use of coal. The GHG emissions reduction for steel of $5 \%$ over that same period is comparatively more modest, as recycling rates evolve at a slower pace. The scrap steel to be reconditioned as secondary steel takes some time to return to the electric steel furnaces as the service time is generally long. However, steel is extensively used in the manufacture of wind turbines - up to 500 tons can be required on a $9 \mathrm{MW}$ model. Therefore, small increments in the recycled content rate lead to significant potential reduction of GHG emissions.

\subsubsection{The service time}

In this section, the sensitivity of the length of service time on the GHG emissions per kWh produced of the different wind turbine models contained in the 1-MW set is tested while the technological and spatial parameter values are kept 
fixed. All the models presented are manufactured in 2002 - the year where most wind turbines in that set were manufactured - and benefit from an assumed value for wind availability at full load of 3,000 hours, which corresponds to the current average wind load in Denmark [42]. The only varying parameter value in each group of wind turbine models is the duration of the service time.

The results shown in Figure 7.b confirm that the length of service time has a major influence on the GHG emissions per $\mathrm{kWh}$ produced. In fact, for some wind turbine models, the most extreme variation in the service time leads to a $100 \%$ difference in terms of GHG emissions per $\mathrm{kWh}$ produced between the best and worst performing wind turbines (see model "NM 52/900").

\subsection{Geographical influence}

Considering the measured electricity production allows highlighting two important efficiency-related aspects:

- i) the efficiency of the transformation of the wind kinetic energy into electrical power, which refers to the technological ability of wind turbines to reach a certain power output at different wind speeds. This efficiency is determined by the power curve.

- ii) the productivity, which is conditioned by the previously presented power curve and the local wind resource. This productivity can be represented by the number of equivalent hours of wind at a speed that allows the turbines to operate at full load. This is also synonymous to the notion of capacity factor.

Figure 8 shows the sensitivity of parameters associated to the location of the wind turbine during the use phase (i.e. during the electricity production phase) on the GHG emissions of the different wind turbine models contained in the 1MW set. All the models presented are manufactured in 2002 with a service time of 20 years and an annual electricity production that equals their respective median registered production value, to reflect exclusively the influence of local wind availability. As explained in section 2.3 , the median value has been considered to exclude extreme nonrepresentative value such as the first year of production for a wind turbine installed in December. This allows for keeping technological and temporal parameters fixed to assess the sensitivity of spatial parameters (the annual number of hours of available wind at full load, essentially) on the results. The amount of electricity produced over the service time of the wind turbine is influential on the GHG emissions per $\mathrm{kWh}$ produced, as depicted in Figure 8 . The $90 \%$ distribution interval is significantly spread for some wind turbine models. 
Influence of location on the carbon footprint per kWh produced, grouped by models manufactured in 2000

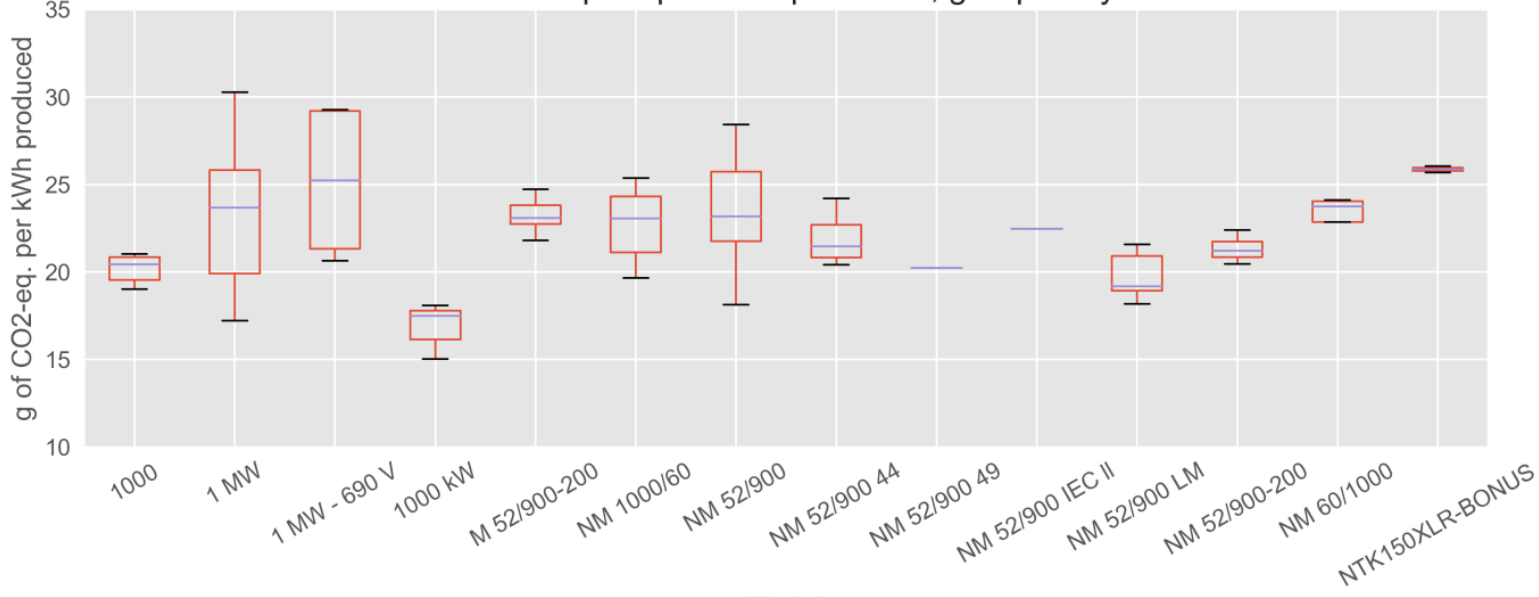

Model

Figure 8: Dispersion of the GHG emissions per kWh produced due to the local wind availability for different wind turbine models manufactured in 2002.

This is also confirmed by looking at the median yearly electricity production for the five sets of wind turbines, as shown in Figure 9. It can be seen that the $90 \%$ distribution interval of the 500-kW and 1-MW sets overlap. This indicates that a well-located $500 \mathrm{~kW}$ wind turbine can potentially produce as much as a 1-MW wind turbine for which the location has not been ideal. Moreover, the $90 \%$ distribution interval of the 2-MW set indicates that a well-located wind turbine may produce more than twice as much than a similar wind turbine not ideally located. It is worth noting that 2 MW onshore wind turbines with larger rotors generally produce more than $6 \mathrm{GWh} /$ year with an average load factor of $38 \%$ compared to the $27 \%$ value for wind turbines with a rotor diameter lower or equal to $80 \mathrm{~m}$. Using larger rotors enables capturing more kinetic energy from the moving air and producing more power at a given wind speed. Despite a higher impact caused by a heavier tower to support the larger rotor, the increase of the electricity output generally more than compensates the difference. However, while locations with optimal wind availability are ideal, they are usually limited within an area such as Denmark. Hence, placing wind turbines in sub-optimal locations still present an environmentally superior alternative to fossil-based energy technologies as it helps to improve the overall electricity supply mix. Usually, offshore locations benefit from a more stable and abundant wind resource, as illustrated in Figure 9. Although in this case, the narrowness of the distribution may also be partially explained by the fact that 80 of the 104 wind turbines are operated in the same wind farm. This section demonstrates that the electricity production can vary dramatically even between wind turbines of a same model sharing a similar power curve. It underlines the importance of the spatial parameters, notably the productivity (or capacity factor), in shaping electricity production and ultimately affecting the environmental performances of wind turbines. 


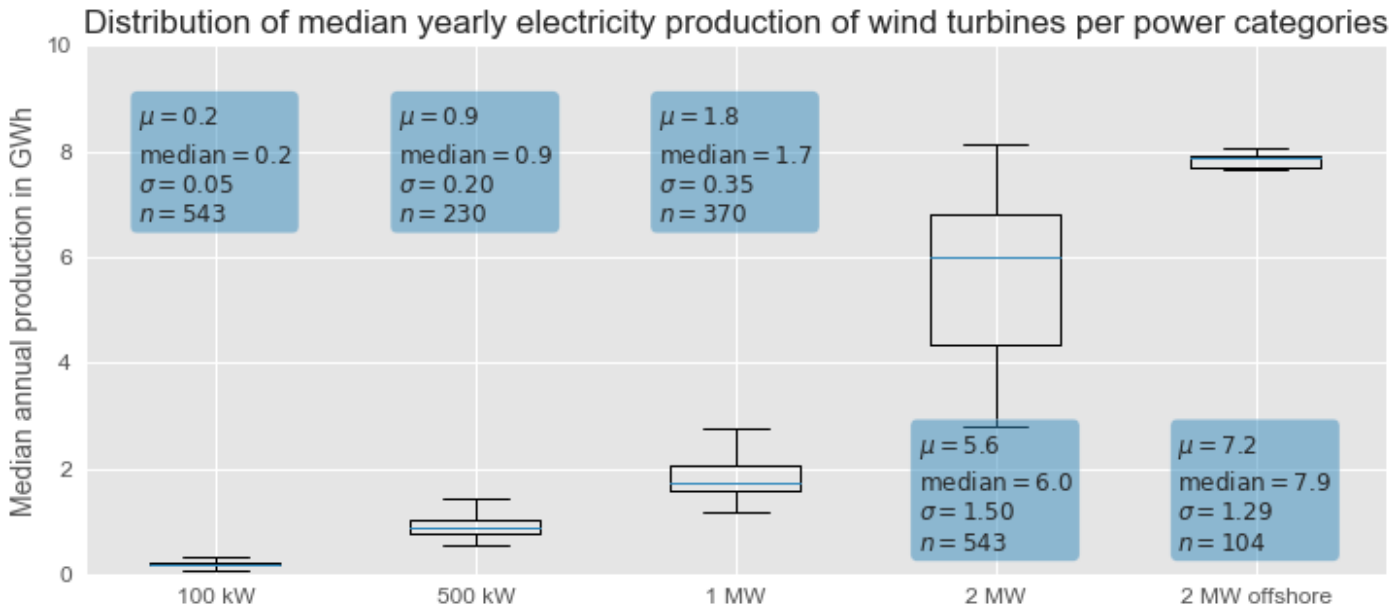

Figure 9: Dispersion of median yearly electricity production of wind turbines per power categories. The blue horizontal line is the median value. Vertical rectangles represent $50 \%$ of the distribution. Vertical black intervals represent $90 \%$ of the distribution. Outlying values are computed but not displayed.

\section{Comparison with previous studies}

A review of existing studies on wind turbine systems is done considering both process-based LCA and hybridized forms of LCA to position the results obtained for the five sets of wind turbines, expressed as GHG emissions per $\mathrm{kWh}$ in Figure 10. The emissions dispersion intervals for the five sets of wind turbines are similar to what has been presented in Figure 5.b. As argued in the Introduction section, most LCA studies of wind turbine systems, and RES in general, cannot be fairly compared because of differing model-related assumptions, among others. Hence, this comparison is not an attempt to explain the difference between the results of this study and what has been published previously $[15,18,51,43-50]$, but rather to confirm that they fall within acceptable ranges. 
Figure 10 Comparison with previous studies expressed as GHG emissions per $k$ Wh

In Figure 10 two outliers for the $2 \mathrm{MW}$ offshore turbines are worth discussing - see the orange dots. These values are more than twice the average GHG emissions per kWh obtained for the corresponding set of wind turbines. They are obtained by combining Multi-Regional Input-Output (MRIO) tables with process-based LCA, also called hybrid LCA. Such observation is coherent with the findings of Wiedmann et al. [48] who underlined that hybrid LCA for wind turbines return impacts that are consistently higher than those obtained with a purely process-based LCA approach. This seems to confirm here once again. The authors argued that process-based LCA may lead to truncate a significant part of the inventory and to ultimately underestimate emissions. However, the current resolution of most common MRIO can restrain the possibilities to distinguish specific materials within the inventory, limiting oneself to families of products. For example, low-alloy and stainless steel, two steel products extensively involved in the inventory of wind turbines, are two materials with significantly different environmental impacts (approximately $2 \mathrm{kgCO}_{2}$-eq./kg of low-alloy steel against $5 \mathrm{kgCO}_{2}$-eq./kg of stainless steel according to [38] using IPCC's GWP100a characterization factors). Such MRIO as Exiobase v.3 [52] would treat both steel products indifferently as "Basic iron and steel and of ferro-alloys and first products thereof'. It is therefore not hard to imagine that what is gained in completeness could potentially be lost as increased inaccuracy due to the coarse resolution of the MRIO data. Nevertheless, the use of a hybrid approach based on MRIO could add completeness to the present method and should be considered a potential direction for future research. 


\section{Conclusion}

This study highlights the importance of considering the variability and uncertainty induced by parameters of technological, spatial and temporal nature in LCA models of RES in general, illustrated with a significant sample of wind turbines in Denmark. Great variability in results has been found within sets of wind turbines with a similar nominal power output. Looking at the causes of such variability, diversity of designs (material intensity), intended applications (onshore and offshore use), wind availability, service time and the year of manufacture have a major influence on the environmental performances of wind turbines. Instead of generic models provided by common LCI databases or EPD, one should welcome more complex parameterized inventories that embrace technological, geographical and temporal variability, limit uncertainty and allow the comparison of different models on equal grounds. If LCA is to gain in precision for assessing potential wind turbine farms, there is a need in the future for models that generate LCI tailored to specific projects. They would ideally allow including the specificities associated to the wind turbine models considered and the context and location of use.

Access to such parameterized models would support better-informed decisions as wind power cannot be reduced to one single wind turbine installed in generic conditions. It would also produce a more accurate reporting of GHG emissions associated to wind power generation in general. At the national level, there is a need for developing nation-wide wind turbine fleet inventories to improve the environmental assessment of electrical systems with a high share of renewable energy. It is precisely the purpose of LCA_WIND_DK, an online LCA tool under development that will rely on the parameterized model presented in this study to provide detailed environmental statistics on all past, current and future wind turbines in Denmark.

Such methodology developed along the four-step sequence could be applied, for example, to other RES and/or to other areas at regional and national level. Finally, the approach seems suitable for a large range of energy systems, especially for RES for which most of the material and energy requirements occur during the manufacture and installation phases: photovoltaic panels, geothermal heat pumps, tidal and wave energy converters.

\section{Acknowledgements}

The authors wish to thank the anonymous reviewers for contributing to the betterment of this study. In addition, the authors express their gratitude to the Danish Ministry of Energy for providing detailed and comprehensive data on the national wind turbine fleet. Finally, the authors wish to thank Christopher Mutel and the developers behind Brightway, the LCA framework used in this study. 


\section{References}

[1] K. Friedrich, M. Lukas, Wind Energy Statistics in Europe: Onshore and Offshore, springer, 2017. doi:10.1007/978-3-319-45659-1_36.

[2] IEA, CO2 EMISSIONS FROM FUEL COMBUSTION: OVERVIEW, (2017). https://www.iea.org/publications/freepublications/publication/co2-emissions-from-fuel-combustion----2017edition---overview.html.

[3] R. Turconi, D. Tonini, C. Nielsen, C.G. Simonsen, T. Astrup, Environmental impacts of future low-carbon electricity systems: Detailed life cycle assessment of a Danish case study, 132 (2014) 66-73. doi:10.1016/j.apenergy.2014.06.078.

[4] E.G. Hertwich, T. Gibon, E.A. Bouman, A. Arvesen, S. Suh, G.A. Heath, J.D. Bergesen, A. Ramirez, M.I. Vega, L. Shi, Integrated life-cycle assessment of electricity-supply scenarios confirms global environmental benefit of low-carbon technologies, Proc Natl. Acad Sci. 112 (2015) 6277-6282. doi:10.1073/pnas.1312753111.

[5] R. Garcia, P. Marques, F. Freire, Life-cycle assessment of electricity in Portugal, Appl Energ. 134 (2014) 563572. doi:10.1016/j.apenergy.2014.08.067.

[6] E. Santoyo-Castelazo, H. Gujba, A. Azapagic, Life cycle assessment of electricity generation in Mexico, Energy. 36 (2011) 1488-1499. doi:10.1016/j.energy.2011.01.018.

[7] D. García-Gusano, D. Garraín, J. Dufour, Prospective life cycle assessment of the Spanish electricity production, 75 (2017) 21-34. doi:10.1016/j.rser.2016.10.045.

[8] R. Brizmohun, T. Ramjeawon, A. Azapagic, Life cycle assessment of electricity generation in Mauritius, J Clean Prod. 106 (2015) 565-575. doi:10.1016/j.jclepro.2014.11.033.

[9] F. Asdrubali, G. Baldinelli, F. D’Alessandro, F. Scrucca, Life cycle assessment of electricity production from renewable energies: Review and results harmonization, 2015. doi:10.1016/j.rser.2014.10.082.

[10] Energistyrelsen, Månedlig og årlig energistatistik, (2017). https://ens.dk/service/statistik-data-noegletal-ogkort/maanedlig-og-aarlig-energistatistik.

[11] T. Zimmermann, Parameterized tool for site specific LCAs of wind energy converters, 18 (2013) 49-60. doi:10.1007/s11367-012-0467-y.

[12] P. Padey, R. Girard, D. le Boulch, I. Blanc, From LCAs to Simplified Models: A Generic Methodology Applied 
to Wind Power Electricity, 47 (2013) 1231-1238. doi:10.1021/es303435e.

[13] M. Lenzen, J. Munksgaard, Energy and CO2 life-cycle analyses of wind turbines - review and applications, Renew. Energy. 26 (2002) 339-362. doi:10.1016/S0960-1481(01)00145-8.

[14] B. Guezuraga, R. Zauner, W. Pölz, Life cycle assessment of two different 2 MW class wind turbines, (2012).

[15] E. Martínez, F. Sanz, S. Pellegrini, E. Jiménez, Life-cycle assessment of a 2-MW rated power wind turbine: CML method, (2009).

[16] B. Tremeac, F. Meunier, Life cycle analysis of 4.5 MW and 250W wind turbines, (2009).

[17] J. Weinzettel, M. Reenaas, C. Solli, E.G. Hertwich, Life cycle assessment of a floating offshore wind turbine, 34 (2009) 742-747. doi:10.1016/j.renene.2008.04.004.

[18] L. Schleisner, Life cycle assessment of a wind farm and related externalities, Renew. Energy. 20 (2000) 279288. doi:10.1016/S0960-1481(99)00123-8.

[19] Varun, I.K. Bhat, R. Prakash, LCA of renewable energy for electricity generation systems-A review, 13 (2009) 1067-1073. doi:10.1016/j.rser.2008.08.004.

[20] I. Kubiszewski, C.J. Cleveland, P.K. Endres, Meta-analysis of net energy return for wind power systems, 35 (2010) 218-225. doi:10.1016/j.renene.2009.01.012.

[21] A. Arvesen, E.G. Hertwich, Assessing the life cycle environmental impacts of wind power: A review of present knowledge and research needs, 16 (2012) 5994-6006. doi:10.1016/j.rser.2012.06.023.

[22] Energinet.dk, Stamdataregister for vindkraftanlæg, (2017). https://ens.dk/service/statistik-data-noegletal-ogkort/data-oversigt-over-energisektoren.

[23] C. Mutel, Brightway: An open source framework for Life Cycle Assessment, 2 (2017). doi:10.21105/joss.00236.

[24] R.K. Pachauri, M.R. Allen, V.R. Barros, J. Broome, W. Cramer, R. Christ, J.A. Church, L. Clarke, Q. Dahe, P. Dasgupta, Climate change 2014: synthesis Report. Contribution of working groups I, II and III to the fifth assessment report of the intergovernmental panel on climate change, (2014).

[25] Energinet.dk, Technical Project Description for Offshore Wind Farms (200 MW), (2015). http://mst.dk/media/134714/offshore-technical-project-description-generic_vesterhav-nord_april-2015.pdf.

[26] M. Pierrot, Wind energy database, (2017). https://www.thewindpower.net/index_en.php. 
580 [27] Nexans, Integrated cable solutions for offshore wind development, (2015).

581 [28] Nexans, XLPE insulated cable $150 \mathrm{kV},(2017)$.

582 [29] Nexans, 2XS(FL)2YRAA RM 19/33 (36)kV, (2016).

583 [30] P. Powerlink, Giulio Verne Cable Laying Ship Specification, (2008).

584 [31] ABB-T\&D-S.p.A., Large Distribution Transformer 10 MVA, (2003).

585 https://library.e.abb.com/public/57c1d5721712c65fc1256de9003d9401/10 MVA.pdf.

586 [32] ABB-Power-Transmission, Power transformer TrafoStar 500 MVA, (2000). https://library.e.abb.com/public/566748ad75116903c1256d630042f1af/ProductdeclarationStarTrafo500.pdf.

[33] Y. Kieffel, F. Biquez, SF\&lt;inf\&gt;6\&lt;/inf\&gt; alternative development for high voltage switchgears, in: 2015 IEEE Electr. Insul. Conf., IEEE, 2015: pp. 379-383. doi:10.1109/ICACACT.2014.7223577.

[34] M. Hyrenbach, S. Zache, Alternative insulation gas for medium-voltage switchgear, in: 2016 Pet. Chem. Ind.

[35] S. Wartmann, J. Harnisch, REDUCTIONS OF SF 6 EMISSIONS FROM HIGH AND MEDIUM VOLTAGE

[36] J. Blackman, SF 6 Leak Rates from High Voltage Circuit Breakers -U.S. EPA Investigates Potential ELECTRICAL EQUIPMENT IN EUROPE, 2005.

https://www.ecofys.com/files/files/ecofys_2005_reductionssf6emissions.pdf (accessed June 20, 2018). Greenhouse Gas Emissions Source, U.S. Environ. Prot. Agency. (2003). https://www.epa.gov/sites/production/files/2016-02/documents/leakrates_circuitbreakers.pdf (accessed June 20, 2018).

[39] W. Stahl, Steel production in Germany by process, (2017). http://en.stahlhttps://ens.dk/sites/ens.dk/files/Forskning_og_udvikling/strategy_for_extending_the_useful_lifetime_of_a_win d_turbine_2016.pdf. 
[41] J.K. Kaldellis, D. Apostolou, Life cycle energy and carbon footprint of offshore wind energy. Comparison with onshore counterpart, Renew Energ. 108 (2017) 72-84. doi:10.1016/j.renene.2017.02.039.

[42] Energistyrelsen, Quality Wind: Improving performance of wind turbines, (2016). https://ens.dk/sites/ens.dk/files/Globalcooperation/qualitywind.pdf.

[43] E.A. Smoucha, K. Fitzpatrick, Life Cycle Analysis of the Embodied Carbon Emissions from 14 Wind Turbines with Rated Powers between 50 Kw and 3.4 Mw, J. Fundam. Renew. Energy Appl. 6 (2016). doi:10.4172/20904541.1000211.

[44] M.R. Kabir, B. Rooke, G.D.M. Dassanayake, B.A. Fleck, Comparative life cycle energy, emission, and economic analysis of $100 \mathrm{~kW}$ nameplate wind power generation, Renew. Energy. 37 (2012) 133-141. doi:10.1016/J.RENENE.2011.06.003.

[45] K.R. Voorspools, E.A. Brouwers, W.D. D'haeseleer, Energy content and indirect greenhouse gas emissions embedded in 'emission-free' power plants: results for the Low Countries, Appl. Energy. 67 (2000) 307-330. doi:10.1016/S0306-2619(00)00016-7.

[46] M.J. Khan, M.T. Iqbal, Dynamic modeling and simulation of a small wind-fuel cell hybrid energy system, Renew. Energy. 30 (2005) 421-439. doi:10.1016/J.RENENE.2004.05.013.

[47] N. Jungbluth, C. Bauer, R. Dones, R. Frischknecht, Life Cycle Assessment for Emerging Technologies: Case Studies for Photovoltaic and Wind Power (11 pp), Int. J. Life Cycle Assess. 10 (2005) 24-34. doi:10.1065/lca2004.11.181.3.

[48] T.O. Wiedmann, S. Suh, K. Feng, M. Lenzen, A. Acquaye, K. Scott, J.R. Barrett, Application of Hybrid Life Cycle Approaches to Emerging Energy Technologies - The Case of Wind Power in the UK, Environ. Sci. Technol. 45 (2011) 5900-5907. doi:10.1021/es2007287.

[49] F. Querini, S. Dagostino, S. Morel, P. Rousseaux, Greenhouse Gas Emissions of Electric Vehicles Associated with Wind and Photovoltaic Electricity, Energy Procedia. 20 (2012) 391-401. doi:10.1016/J.EGYPRO.2012.03.038.

[50] T. Songlin, Z. Xiliang, W. Licheng, Life cycle analysis of wind power: A case of Fuzhou, Energy Procedia. 5 (2011) 1847-1851. doi:10.1016/J.EGYPRO.2011.03.315.

[51] ELSAM, Life Cycle Assessment of offshore and onshore sited wind farms, (2004). https://www.vestas.com/ /media/vestas/about/sustainability/pdfs/lca_v80_2004_uk.ashx (accessed June 14, 

2018).

636 [52] K. Stadler, R. Wood, T. Bulavskaya, C.-J. Södersten, M. Simas, S. Schmidt, A. Usubiaga, J. Acosta-Fernández, 637 J. Kuenen, M. Bruckner, S. Giljum, S. Lutter, S. Merciai, J.H. Schmidt, M.C. Theurl, C. Plutzar, T. Kastner, N. Eisenmenger, K.-H. Erb, A. de Koning, A. Tukker, EXIOBASE 3: Developing a Time Series of Detailed Environmentally Extended Multi-Regional Input-Output Tables, J. Ind. Ecol. 22 (2018) 502-515.

640 doi:10.1111/jiec.12715.

641 